\title{
Physical activity and dietary patterns: a health risk behavior cluster pattern analysis of students in a Caribbean medical school
}

\author{
Samal Nauhria', Sanjib Das², Kusai M Alsalhanie ${ }^{3}$, Anmol Goyal ${ }^{4}$, Brijinder K Gupta ${ }^{5}$, \\ Olawole Akinboboye ${ }^{6}$, Oghenetega Ehwarieme ${ }^{6}$ \\ ${ }^{1}$ Assistant Professor, ${ }^{3}$ Instructor, Department of Pathophysiology, ${ }^{2}$ Associate Professor, Department of Pharmacology \& \\ Clinical Sciences, ${ }^{5}$ Professor, Department of Molecular Sciences, ${ }^{6}$ Student, Department of Basic science MD program, \\ Windsor University School of Medicine, St. Kitts and Nevis, ${ }^{4}$ Assistant Professor, Department of Community Medicine, \\ Maharishi Markandeshwar Medical College and Hospital, Kumarhatti, Solan, Himachal Pradesh, India
}

Background: Collegial effects of variable lifestyle risk behaviors on the high incidence of chronic conditions are pivotal issues in defining overall health and public wellness. Medical students are expected to have a superior understanding of health issues but the majority of them lead an unhealthy lifestyle. Aims and Objectives: This study examined the prevalence and clustering patterns of multiple health risk behaviors among students of a Caribbean medical school. Materials and Methods: A cross-sectional study was conducted among the first and secondyear medical students by using questionnaire which assessed multiple health behaviors including physical activity patterns, fruits, vegetables and breakfast consumption. Age and gender specific clustering patterns of various risk behaviors were identified. Results: Study suggested that male students were more active than female students $(p<0.01)$. Gender non-specific younger age group was more active than older age group $(p<0.001)$. The frequency of breakfast consumption was higher in males $(p<0.01)$. Fruit \& vegetable consumption was higher in older students $(p<0.01)$ irrespective of gender. A cluster of three health risk behavior was found in $10 \%$ of the total students while only $7 \%$ met the recommendations for all three health risk behaviors. BMI of the majority of students $(72 \%)$ was found to be within normal range. The primary motivation for performing physical activity in $35 \%$ students was to lose weight or maintain appearance and in $31 \%$ to eliminate stress. Conclusion: Many medical students still fail to meet the physical activity and dietary recommendations which may be attributed to their busy schedules and academic overload.
http://nepjol.info/index.php/AJMS DOI: 10.3126/ajms.v8i4.17178 E-ISSN: 2091-0576 P-ISSN: 2467-9100

Key words: Medical school students, Physical activity patterns, Dietary habits,

Health risk behaviors

\section{INTRODUCTION}

Lack of physical activity and poor nutrition are very well known associated risk factors for non-communicable chronic diseases. ${ }^{1}$ According to the Centers for Disease Control (CDC), cardiovascular diseases are the leading cause of death in the United States. Overweight and obesity being the major contributors for the same. ${ }^{2}$

Association of an individual's behavior with health risks leading to non-communicable chronic diseases like cardiovascular diseases is broadly acknowledged. A pivotal issue for overall public wellness is that there is a likelihood of collegial effects of variable lifestyle behaviors on the high incidence of chronic conditions thus defining the overall health. ${ }^{3}$

Ample of recent studies have indicated a need for an intervention in the lifestyle patterns of young students. This is primarily because of 2 major reasons. First, the students tend to have disproportionate energy intake levels, and secondly, because of their sedentary lifestyle. These 
behaviors eventually lead to adverse health outcomes not otherwise typical for their age. ${ }^{4}$ Recent studies also indicate very disturbing health trends related to improvements in life expectancy among U.S. young women as compared to men. ${ }^{5}$

The Dietary Guidelines for Americans emphasizes on a healthy diet pattern which includes eating whole grains, fruits, vegetables, lean protein, and low-fat and fat-free dairy products and drinking adequate clean water. "The Physical Activity Guidelines for Americans advises adults to perform moderate intensity activity for at least 150 minutes or vigorous intensity activity for 75 minutes, or a combination of both, along with 2 days of strength training per week". ${ }^{7}$ Physical activity of variable intensities is essential in the young age group because of a high impact on the physical state, overall health and quality of life. ${ }^{8}$

"The Mediterranean diet is considered as being one of the best dietary models as it consists of cereal products, vegetables, fruits, little quantity of animal derivative food products and low amounts of unsaturated fatty acids, cholesterol, sugar, sweets and salt whereas the dietary practices of the United States is considered one of the worst"., 10

A student's life during college is a temporary phase, but is considered to be a critical period for adopting new health behaviors, the lifestyle habits embraced during this stage may pursue as they transition into adulthood. ${ }^{11}$ Thus, a thoughtful exploration of health behavior cluster patterns among young adults can help us in identifying the high-risk groups and further augment strategies for multiple health behavior interventions.

A lower rate of respiratory ailments has also been associated with a higher fruit \& vegetable consumption in the young population and also tends to be protective against cancer later in life. ${ }^{12,13}$ Numerous cross-sectional and longitudinal studies show that adolescents who have a regular routine of eating breakfast are less likely to be overweight as compared to those who skip their breakfast regularly. ${ }^{14,15}$ Research data also suggests that eating breakfast regularly is associated with a healthy BMI in adults. ${ }^{16}$ In spite of overall health benefits, adolescents are still more likely to skip breakfast than any other meal. ${ }^{17}$

An association between physical activity and dietary behaviors in young adults has been described previously in ample research. ${ }^{18}$ Associations have been previously described linking low fruit \& vegetable use and physical inactivity. ${ }^{19}$ It has also been noted that skipping breakfast may lead to physical inactivity. ${ }^{20}$ The existence of multiple risk factors in young adults very often lead to clustering of more than two risk behaviors in one individual. ${ }^{3}$
However, these recommendations are very often poorly realized. It is acknowledged that medical students have a superior understanding of health issues. But due to the vigorous and time-consuming schedule of a medical student, improper dietary habits, and inadequate physical activity, often lead to an unhealthy lifestyle. Monitoring lifestyle, nutrition and physical activity in such subjects are vital because in the future these medical students will themselves be involved in a system which will ensure better public health standards and also promote wellness.

The aim of the present study was to identify clusters of health risk behaviors by objectively assessing physical activity patterns and dietary habits amongst the first and second-year medical degree students of Windsor University School of Medicine, St.Kitts and any measures that could be taken to improve it. It is hypothesized that most of the medical students fail to meet these recommendations due to academic overload. Our research also focuses on gender differences in the health behaviors and considers a broad range of contexts and unique characteristics.

\section{MATERIALS AND METHODS}

\section{Study sample and procedure}

This was a cross-sectional study and data was collected between May 2016 and April 2017. The study procedures were approved by Ethical and Advisory Committee of the Windsor University. Data were obtained from the undergraduate MD program (5 semesters) students along with Pre-Medical program students (4 semesters) with an age group ranging from 17 to 35 years. All the students were given written information about this project. Prior to the study, all the students provided assent before completing written surveys and completing questionnaires. Any student with a few specific chronic ailments (e.g. type 1 diabetes or any condition limiting their physical activity or disrupting their dietary habits) was excluded from the study to avoid errors.

\section{Measures}

Questionnaires were created which collected information about demographics of the students including age, sex, residing location, present semester, average sleeping hours (both weekends and weekdays), height and weight which was used to calculate the body-mass index (BMI). An approximate estimation of socioeconomic status (SES) was based on a student's residence locality (urban or rural).

\section{Student dietary patterns}

The student food intake was assessed using a validated food frequency questionnaire. The students were asked how often they ate fruits and vegetables in the past one week ranging from no use to more than 5 times per day. 
This data was summed up to calculate the frequency of consumption of fruits and vegetables per day. "The current recommendations for fruit and vegetable consumption are 5 servings per day". ${ }^{21}$ Thus, the data was dichotomized into less than 5 times per day or $\geq 5$ times per day. Breakfast consumption was evaluated by asking how often students consumed their breakfast in the past one week. There are still no guidelines for breakfast consumption but it is recommended that parents should encourage youngsters to regularly eat breakfast. So the frequency of breakfast consumption in the last one week was dichotomized into less than 5 days per week or $\geq 5$ days per week.

\section{Physical activity}

A physical activity questionnaire was constructed according to WHO publications and NHANES 2015-2016 guidelines. Participants were instructed to use the accelerometer for a week. Data from the accelerometers was collected separately from the students. General well-being assessment was also done with respect to their physical activity and body weight. Sleep patterns (average sleeping hours; both weekdays and weekends) and sedentary activities such as television viewing were also recorded. Physical activity was assessed as per Physical Activity Questionnaire (PAQ) and metabolic equivalents were thus calculated from the data. Estimation of time spent per day lead to the categorization of subjects with moderate intensityphysical activity (3.0 to 5.9 MET's) and vigorous intensity physical activity $\left(>6.0\right.$ MET's). ${ }^{22}$ Based on the physical activity recommendations foryoung people, calculations were done accordingly; i.e. whetherthey performed an average of 60 minutes per day of MVPA. ${ }^{23}$ Finally, the time spent in MVPA was dichotomized as $<60$ minutes per day or $\geq 60$ minutes per day.

\section{Statistical analyses}

The data analysis was done with IBM SPSS statistics software version 23.0. The data analysis was done for sociodemographic, physical activity and dietary pattern of the study group. To analyze gender, age differences, use of fruit $\&$ vegetables, MVPA and frequency of breakfast, Pearson's chi-squared $(\chi 2)$ tests of significance were applied. These tests of significance were used to compare age-group and gender in the proportion of students who achieved $\geq$ 60 minutes of MVPA per day, and those who consumed fruit $\&$ vegetables $\geq 5$ times per day, and breakfast $\geq$ 5 times per week.

Based on the total number of risk behaviors, a risk grade was worked up for each student (assigned from 0 to 3 ). The proportion of students in each risk behavior combination was determined to examine risk behavior clusters, and Pearson's chi-squared test was further used to observe gender and age differences in the clustering patterns.

\section{RESULTS}

\section{Sample characteristics}

A total of 352 students completed the questionnaires after consent. A slightly higher fraction were females, as compared to male students ( $51 \%$ compared to $49 \%$ ), but had a lower frequency of breakfast consumption on more days (4 days compared to 5 days per week). The age group of the sample ranged from 17 to 35 years. For agerelated behavior comparison, we divided the students into two groups; a gender non-specific younger group from 17-25 years and an older group from 26 to 35 years. The final sample composition was 352 students, with 174 male students, 178 females, 196 young students and 156 older students. This study reflects a study group from a mixed ethnic and multicultural background and $61 \%$ were of a high socio-economic status.

Physical activity, fruit/vegetable, and breakfast behaviors

A majority of the students $(72 \%)$ had the BMI in the normal range of 18.5 to $24.9 \mathrm{~kg} / \mathrm{m}^{2}$ which is a positive finding among medical university students. The most favorite physical activity among the students was to work out (27\%) and cycling was the least favorite (6\%) (Figure 1). The primary reason reported for performing physical activity was to eliminate stress (31.3\%) (Figure 2).

Significant gender differences were seen in MVPA, fruits \& vegetable use and breakfast consumption. The male students had higher MVPA per day compared to females. However, females ate breakfast on fewer days per week $(p<0.01)$. Age-group differences were also evident as younger students (17-25 years) engaged in more MVPA per day compared to older students ( 26 to 35 years) ( $p<0.001)$. Consumption of fruits \& vegetables per day was higher in older students compared to younger students $(p<0.001)$.

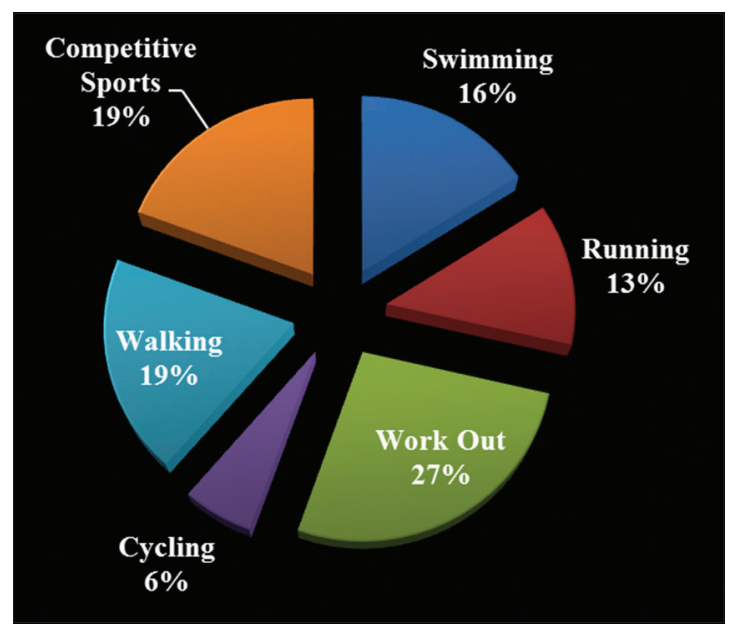

Figure 1: Favorite physical activity among medical students

Asian Journal of Medical Sciences | Jul-Aug 2017 | Vol 8 | Issue 4 
Prevalence of meeting health recommendations

Table 1 shows the age and sex distribution along with the proportion of students meeting the physical activity, fruit/ vegetable, and breakfast consumption recommendations. This study found that a higher proportion of males $(85 \%)$ ate breakfast on more than 5 days per week $(\mathrm{p}<0.01)$ as compared to the female students (68.5\%). A higher percentage of young age group students (30.6\%) met the physical activity guidelines as compared to the older students $(11.5 \%)$. On the other hand, the younger group did not meet the recommended guidelines for fruit/vegetable consumption as compared to the older group $(\mathrm{p}<0.01)$.

Table 2 describes the clustering patterns of the health risk behaviors. Only $6.5 \%$ of the students met the

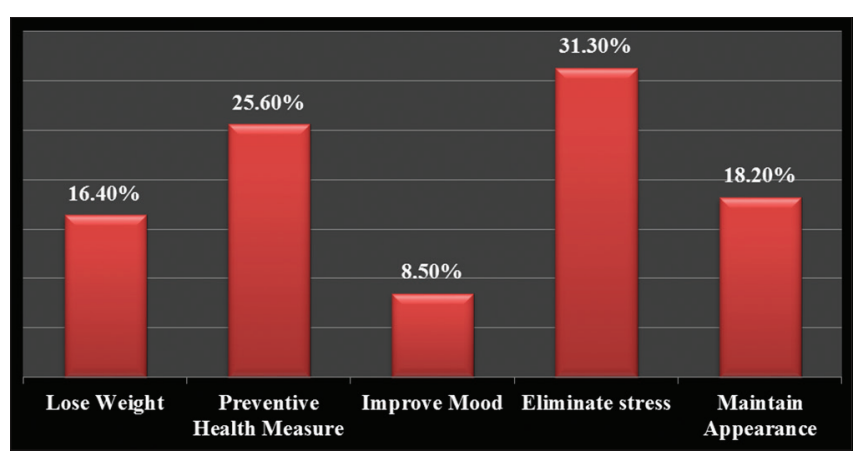

Figure 2: Primary reason for doing exercise recommendations for all the three health risk behaviors. A cluster of three health risk behaviors was seen in almost $10.5 \%$ of the sample which also showed a higher proportion of females $(13.5 \%)$ with all three risk behaviors $(p<0.01)$. The most prevalent two risk behavior cluster consisted of students not meeting the physical activity and fruit/vegetable recommendations. A higher proportion of females $(10.3 \%)$ showed a cluster pattern consisting of not meeting the physical activity and breakfast consumption $(\mathrm{p}<0.01)$ recommendations as compared to males $(1.7 \%)$. The most common single risk factor of not meeting the recommendations for physical activity $(\mathrm{p}<0.01)$ was seen in a higher proportion of males $(37.5 \%)$, compared to females $(24.6 \%)$, and older students $(39 \%)$, compared to young students $(20.4 \%)$. The single risk factor of not meeting the recommendations for fruit $\&$ vegetable consumption was seen in a higher proportion of younger students $(12 \%)$ as compared to older students $(3.6 \%)$ $(\mathrm{p}<0.01)$.

\section{DISCUSSION}

This study describes the physical activity patterns, breakfast routine and fruit/vegetable consumption of both male and female students in a Caribbean medical school. This study reveals that a very small proportion $(6.5 \%)$ of respondents

\begin{tabular}{|c|c|c|c|c|c|}
\hline Parameters & Total (352) & Males (174) & Females (178) & Younger group (196) & Older group (156) \\
\hline \multicolumn{6}{|c|}{ MVPA minutes/day } \\
\hline$<60$ & $274(77.8)$ & $126(72.4)$ & $148(83.1)$ & $136(69.4)$ & $138(88.5)$ \\
\hline$\geq 60$ & $78(22.2)$ & $48(27.6)$ & $30(16.9)$ & $60(30.6)$ & $18(11.5)$ \\
\hline \multicolumn{6}{|c|}{ Fruit/vegetable consumption/day } \\
\hline$<5$ times & $196(55.7)$ & $90(51.7)$ & $106(59.6)$ & $126(64.2)$ & $70(44.9)$ \\
\hline$\geq 5$ times & $156(44.3)$ & $84(48.3)$ & $72(40.4)$ & $70(35.8)$ & $86(55.1)$ \\
\hline \multicolumn{6}{|c|}{ Breakfast consumption/week } \\
\hline$<5$ days & $82(23.3)$ & $26(14.9)$ & $56(31.5)$ & $46(23.5)$ & $36(23.1)$ \\
\hline$\geq 5$ days & $270(76.7)$ & $148(85.1)$ & $122(68.5)$ & $150(76.5)$ & $120(76.9)$ \\
\hline \multicolumn{6}{|c|}{ Risk behaviors } \\
\hline 0 & $23(6.5)$ & $17(9.8)$ & $6(3.4)$ & $15(7.7)$ & $8(5.1)$ \\
\hline 1 & $144(40.9)$ & $81(46.5)$ & $63(35.4)$ & $74(37.8)$ & $70(44.9)$ \\
\hline 2 & $156(44.3)$ & 66 (37.9) & $90(50.6)$ & $96(49)$ & $60(38.5)$ \\
\hline 3 & $37(10.5)$ & $13(7.5)$ & $24(13.5)$ & $17(8.7)$ & $20(12.8)$ \\
\hline
\end{tabular}

Table 2: Multiple risk behavior cluster pattern descriptions

\begin{tabular}{lccc}
\hline Risk behaviors & $\begin{array}{c}\text { Percent } \\
\text { of total }\end{array}$ & $\begin{array}{c}\text { Males (174) } \\
\text { Females (178) }\end{array}$ & $\begin{array}{c}\text { Younger } \\
\text { group (196) }\end{array}$ \\
\hline 3roup (156)
\end{tabular}


successfully met the recommendations for all three of the health behaviors. Another small proportion (10.5\%) failed to achieve all three recommendations. These findings indicate the need for effective strategies to promote healthy lifestyle behaviors among medical students.

Males and younger students had a high MVPA in comparison to females and older students, respectively. These findings are consistent with plentiful previous research showing declines in physical activity in correlation with gender and increasing age..$^{24,25}$ Research based on accelerometer data also shows evidence of the same. ${ }^{26-28}$ This implies that young adulthood years are critical for the development of disparity in physical activity behaviors. ${ }^{29}$ An active adolescent is more likely to become an active adult so it is of utmost importance to promote physical activity during younger age groups. ${ }^{30}$ There is compelling evidence that promoting an active lifestyle to females may be challenging in some situations, and may require assessment of activity preferences and also the choices available to them. ${ }^{31}$

Benefits of physical activity and proper nutrition in terms of preventive and therapeutic effects on health are very well known. Various studies also prove that a students' own attitude towards the health promotion and illness prevention directly influences their levels of physical activity and proper nutritionwhich is vital for future health professionals. ${ }^{25}$ Also, evidence of early risk factors for chronic diseases has been exhibited in medical students. ${ }^{32}$

Students by large $(72 \%)$ had a normal BMI $\left(18.5-24.9 \mathrm{~kg} / \mathrm{m}^{2}\right)$ which was an encouraging finding revealed by this study. Similar findings have been reported from a medical college in India where a normal BMI was observed in the majority of the students. ${ }^{33}$ Students with BMI $\geq 25 \mathrm{~kg} / \mathrm{m}^{2}$ constituted almost one-fourth of our study group. This finding is comparable with a study done among college students of Arizona. ${ }^{34}$ In response to the question regarding primary motivation that drives them to perform physical activities, one-third selected maintenance of physical appearance by achieving weight loss, which indicates that higher BMI may be a motivation for some medical students to perform physical activity. The other reasons quoted by the students to perform physical activity (as a preventive health measure, to eliminate stress, improve mood) were identical to the reasons reported by El-Gilany et al in their study on Egyptian and Saudi medical students. ${ }^{35}$

As compared to males, the females skipped breakfast more frequently which is a consistent finding with previous research. Higher frequency of skipping breakfast in females may be because it is a chosen method of weight control, dieting, or disordered eating despite evidence that skipping breakfast is associated with higher BMI as compared to those who ate breakfast regularly. ${ }^{36}$ Young girls should be educated more about these unhealthy practices and consuming a healthy breakfast on a daily basis should be promoted in schools.

Consumption of fruit and vegetables in males and older age group students was more per day. A lot of reviews have shown such an association between age and fruit and vegetable consumption. Multiple factors which have a positive impact on fruit and vegetable consumption are socio-economic variables, individual preferences, and availability. ${ }^{37}$

The most prevalent multiple risk behaviors found in this study were insufficient physical activity and low fruit and vegetable consumption. This finding is consistent with previous reports showing evidence of such clustering. Pronk et al found that only $10 \%$ of the adults met the recommendations for healthy lifestyle factor guidelines (including healthy weight, no smoking, physical activity and high-quality diet). ${ }^{38}$ Young adult students who frequently skip breakfast tend to have a lower daily energy intake, possibly explaining such clustering. Keski-Rahkonen et al found that breakfast skipping was associated with the infrequent physical activity. ${ }^{39}$

Overall, the female students had a higher number of risk factors related to physical activity and dietary behaviors compared to males. Ample previous research is available which provides evidence for support of promoting genderspecific interventions. As discussed before, aggressive promotion of both physical activity and regular breakfast routine especiallyto young females is needed.

Future research is still required towards finding best approaches of stimulating multiple behavior changes in young adults. Multiple behavior intervention studies in young adults have revealed changes in some behaviors. Noteworthy effect on dietary habits has been noted as compared to physical activity patterns. Previous research indicates very little co-variation within dietary habits, physical activity, and sedentary behavior. This suggests that to improve these behaviors there is a need to include specific intervention programs for each target behavior of interest in young medical students. Interventions targeting multiple health behaviors (e.g. physical activity and dietary habits) have been shown to be associated with less overall behavior change, compared to interventions targeting a single (e.g. physical activity pattern alone) health behavior. Further research focused on innovative intervention methods for achieving multiple health behavior changes in adolescents and young adults is required. ${ }^{3}$ 
This study described potential clustering patterns of breakfast consumption along with fruit/vegetable consumption and objectively measured physical activity in medical students in a Caribbean medical school. Windsor University School of Medicine (WUSOM) is a private medical school in St.Kitts, admitting the majority of students from the United States, Canada, Nigeria and other countries to the undergraduate medical (MD) course. The results thus achieved reflect a group of students from a multicultural and variable ethnicity and not a group from any particular community or country. There are some limitations in this study which need to be addressed in future research. One limitation was compliance issue when using an accelerometer. ${ }^{40}$ Fruit and vegetable consumption levels reported by students in this study may be higher because of medical knowledge, which reflects the difficulties in assessing diet by using self-report methods. Some differences in fruit/vegetable consumption have been previously reported according to socio-economic status; obviously, those from higher socio-economic status consume more fruits and vegetables. ${ }^{41}$

\section{CONCLUSION}

Less physical activity and improper dietary behaviors often occur as a cluster as many medical students still fail to meet specified recommendations for their age. There are notable differences in dietary and physical activity behaviors in young males and females, as well as between younger and older medical students which should be taken into consideration, while still more research is required to find new strategies for promoting change in multiple health behaviors among them. The available evidence supports the potential effectiveness of the inclusion of physical activity counseling in medical school education. The introduction of a fitness center in the school campus recently has been done to further substantiate the fact that physical activity and proper nutrition are the cornerstones of disease prevention and treatment.

\section{REFERENCES}

1. WHO, Global Action Plan for the Prevention and Control of Noncommunicable Diseases 2013-2020, World Health Organization, Geneva, Switzerland, 2013.

2. Heron M and Anderson RN. Changes in the Leading Cause of Death: Recent Patterns in Heart Disease and Cancer Mortality. NCHS Data Brief 2016;(254):1-8.

3. Olson JS, Hummer RA and Harris KM. Gender and Health Behavior Clustering among U.S. Young Adults. Biodemography and Social Biology [Internet]. 2017 Jan 2 [cited 2017 Apr 19];63(1):3-20. Available from: http://dx.doi.org/10.108 0/19485565.2016.1262238.

4. Anthony D, George P and Eaton CB. Cardiac risk factors: new cholesterol and blood pressure management guidelines. FP
Essent 2014; 421:28-43.

5. Kindig DA and Cheng ER. Even as mortality fell in most US counties, female mortality nonetheless rose in 42.8 percent of counties from 1992 to 2006. Health Aff (Millwood) 2013;32(3):451-458.

6. Mosher A, Piercy K, Webber B, Goodwin S, Casavale K and Olson R. Dietary Guidelines for Americans. American Journal of Lifestyle Medicine 2016;10(1):23-35.

7. Hechanova R, Wegler $\mathrm{J}$ and Forest $\mathrm{C}$. Exercise. Journal of the American Academy of Physician Assistants 2017;30(4):17-22.

8. Grygiel-Górniak B, Tomczak A, Krulikowska N, Przysławski J, Seraszek-Jaros A and Kaczmarek E. Physical activity, nutritional status, and dietary habits of students of a medical university. Sport Sciences for Health 2016;12(2):261-267.

9. Bielak J, Krzyszycha R and Szponar B. Evaluation of dietary habits and other forms of behaviour of students from Lublin. Annales UMCS Sectio D 2006;61(2):874-879.

10. Skoczńska A. The role of nutrition in patients diagnosed with metabolic syndrome. Endokrynol Otyłość Zaburz Przem Mat 2011;7(1):25-33.

11. El Ansari W, Stock $C$ and Mikolajczyk R. Relationships between food consumption and living arrangements among university students in four European countries - A cross-sectional study. Nutrition Journal. 2012;11(1).

12. Antova T, Pattenden S, Nikiforov B, Leonardi GS, Boeva B, Fletcher $\mathrm{T}$, et al. Nutrition and respiratory health in children in six Central and Eastern European countries. Thorax 2003; 58(3):231-236.

13. Maynard M. Fruit, vegetables, and antioxidants in childhood and risk of adult cancer: the Boyd Orr cohort. Journal of Epidemiology \& Community Health 2003;57(3):218-225.

14. Barton B, Eldridge A, Thompson D, Affenito S, StriegelMoore R, Franko D, et al. The Relationship of Breakfast and Cereal Consumption to Nutrient Intake and Body Mass Index: The National Heart, Lung, and Blood Institute Growth and Health Study. Journal of the American Dietetic Association 2005; 105(9):1383-1389.

15. Albertson A, Franko D, Thompson D, Eldridge A, Holschuh N, Affenito S, et al. Longitudinal Patterns of Breakfast Eating in Black and White Adolescent Girls. Obesity 2007;15(9):2282-2292.

16. Megson M, Wing R and Leahey TM. Effects of breakfast eating and eating frequency on body mass index and weight loss outcomes in adults enrolled in an obesity treatment program. J Behav Med 2017;21;1-7.

17. Dwyer JT, Evans M, Stone EJ, Feldman HA, Lytle L, Hoelscher D, et al. Adolescents' eating patterns influence their nutrient intakes. J Am Diet Assoc 2001;101(7):798-802.

18. Moreno-Gómez C, Romaguera-Bosch D, Tauler-Riera P, Bennasar-Veny M, Pericas-Beltran J, Martinez-Andreu S, et al. Clustering of lifestyle factors in Spanish university students: the relationship between smoking, alcohol consumption, physical activity and diet quality. Public Health Nutr 2012;15(11):2131-2139.

19. Tomasone JR, Meikle N and Bray SR. Intentions and Trait Selfcontrol Predict Fruit and Vegetable Consumption During the Transition to First-Year University. Journal of American College Health 2015; 63:172-179.

20. Cohen B, Evers S, Manske S, Bercovitz K and Edward HG. Smoking, physical activity and breakfast consumption among secondary school students in a southwestern Ontario community. Can J Public Health 2003; 94(1):41-44.

21. U.S. Department of Health and Human Services and U.S. Department of Agriculture. 2015-2020 Dietary guidelines for Americans.8;2015. 
22. Gomersall S, Ng N, Burton N, Pavey T, Gilson N and Brown W. Estimating Physical Activity and Sedentary Behavior in a FreeLiving Context: A Pragmatic Comparison of Consumer-Based Activity Trackers and Acti Graph Accelerometry. Journal of Medical Internet Research 2016; 18(9):e239.

23. Garber CE, Blissmer B, Deschenes MR, Franklin BA, Lamonte MJ, Lee I-M, et al. American College of Sports Medicine position stand. Quantity and quality of exercise for developing and maintaining cardiorespiratory, musculoskeletal, and neuromotor fitness in apparently healthy adults: guidance for prescribing exercise. Med Sci Sports Exerc 2011;43(7):1334-1359.

24. Wang $\mathrm{ZH}$, Dong $\mathrm{YH}$, Song $\mathrm{Y}$, Yang $\mathrm{ZP}$ and Ma J. [Analysis on prevalence of physical activity time $<1$ hour and related factors in students aged 9-22 years in China, 2014]. Zhonghua Liu Xing Bing XueZaZhi 2017; 38(3):341-345.

25. Liang MT, Dombrowski HT, Allen TW, Chang CO, Andriulli J, Bastianelli $M$, et al. Do medical students' knowledge and attitudes about health and exercise affect their physical fitness? J Am Osteopath Assoc1993; 93:10028-10032.

26. Pizarro AN, Schipperijn J, Ribeiro JC, Figueiredo A, Mota J and Santos MP. Gender Differences in the Domain-Specific Contributions to MVPA, Accessed by GPS. J Phys Act Health 2017;1-17.

27. Hesketh K, Crawford D and Salmon J. Children's television viewing and objectively measured physical activity: associations with family circumstance. Int J Behav Nutr Phys Act 2006; 3:36.

28. Bagley S, Salmon J and Crawford D. Family structure and children's television viewing and physical activity. Med Sci Sports Exerc 2006; 38(5):910-918.

29. Mooses K, Mägi K, Riso E, Kalma M, Kaasik P and Kull M. Objectively measured sedentary behaviour and moderate and vigorous physical activity in different school subjects: a crosssectional study. BMC Public Health 2017;17(1).

30. Ruiz-Trasserra A, Pérez A, Continente X, O’Brien K, Bartroli M, Teixidó-Compaño $\mathrm{E}$, et al. Patterns of physical activity and associated factors among teenagers from Barcelona (Spain) in 2012. GacSanit [Internet]. [cited 2017 Apr 20]; Available from: http://www.gacetasanitaria.org/en/patterns-physical-activityassociated-factors/avance/S0213911116302552.
31. Yungblut HE, Schinke RJ and McGannon KR. Views of Adolescent Female Youth on Physical Activity During Early Adolescence. J Sports Sci Med 2012;11(1):39-50.

32. Sajwani RA, Shoukat S, Raza R, Shiekh MM, Rashid Q, Siddique MS, et al. Knowledge and practice of healthy lifestyle and dietary habits in medical and non-medical students of Karachi, Pakistan. J Pak Med Assoc 2009; 59:650-655.

33. Yadav S, Saini P, Khan Z, Bachloo T, Kumar R and Singh J. Assessment of body mass index among undergraduate medical students-a cross-sectional study from the Medical College of Haryana. International Journal of Medical Science and Public Health 2016;5(4):705.

34. Vargas P, Flores M and Robles E. Sleep Quality and Body Mass Index in College Students: The Role of Sleep Disturbances. Journal of American College Health 2014;62(8):534-541.

35. El-Gilany A and El-Masry R. Physical Inactivity among Egyptian and Saudi Medical Students. TAF Prev Med Bull 2011; 10:35-44.

36. Kumar C, Revannasiddaiah N, Savanthe A and Patel P. Dietary Habits of Undergraduate Medical Students - A Cross-Sectional Study. Annals of Health and Health Sciences 2014;1(1):55.

37. Tanton J, Dodd LJ, Woodfield L and Mabhala M. Eating Behaviours of British University Students: A Cluster Analysis on a Neglected Issue. Advances in Preventive Medicine 2015; 2015:1-8.

38. Pronk NP, Anderson LH, Crain AL, Martinson BC, O'Connor PJ, Sherwood NE, et al. Meeting recommendations for multiple healthy lifestyle factors. Prevalence, clustering, and predictors among adolescent, adult, and senior health plan members. Am J Prev Med 2004;27(2 Suppl):25-33.

39. Keski-Rahkonen A, Kaprio J, Rissanen A, Virkkunen M and Rose R. Breakfast skipping and health-compromising behaviors in adolescents and adults. European Journal of Clinical Nutrition 2003;57(7):842-853.

40. Trost SG, Mclver KL and Pate RR. Conducting accelerometerbased activity assessments in field-based research. Med Sci Sports Exerc 2005; 37(11 Suppl):S531-43.

41. Nelson M, Erens B, Bates B, Church $S$ and Boshier T. Low income diet and nutrition survey. Summary of key findings. Food Standards Agency. $1^{\text {st }}$ ed. Norwich: TSO; 2007.

\section{Authors Contribution:}

SN-Concept and design of the study, literature search, reviewed the literature, manuscript preparation, statistically analyzed and interpreted data and critical revision of the manuscript; SD- Reviewed the literature, manuscript preparation and critical revision of the manuscript; KMA- Reviewed the literature, manuscript preparation and critical revision of the manuscript; AG- Statistically analyzed and interpreted data, and critical revision of the manuscript; BKG- Reviewed the literature, manuscript preparation; OA- Collected data and review of literature and helped in preparing first draft of manuscript; OE- Collected data and review of literature and helped in preparing first draft of manuscript.

\section{Work attributed to:}

Department of Pathology, Windsor University School of Medicine, St.Kitts \& Nevis

\section{Orcid ID:}

Dr. Samal Nauhria: (i) http://orcid.org/0000-0001-7373-2606

Dr. Sanjib Das: (1) http://orcid.org/0000-0001-9457-466X

Dr. Kusai Alsalhanie: (1) http://orcid.org/0000-0002-1978-5376

Dr. Anmol Goyal: (1) http://orcid.org/0000-0001-9430-0650

Dr. Brijinder Gupta: (1) http://orcid.org/0000-0002-1697-6775

Dr. Olawole Akinboboye: (1) http://orcid.org/0000-0001-8327-9024

Dr. Oghenetega Ehwarieme: (i) http://orcid.org/0000-0002-6672-869X

Source of Support: Windsor University School of Medicine, Cayon, St.Kitts \& Nevis, Conflict of Interest: Nil. 